\begin{tabular}{|c|c|c|c|}
\hline Satish Maharaj, MD & Drew Murray, MD & Simone Chang, MD & Kamila Cisak, MD \\
\hline James Graham Brown Cancer Center, & James Graham Brown Cancer Center, & James Graham Brown Cancer Center, & James Graham Brown Cancer Center, \\
\hline $\begin{array}{l}\text { University of Louisville School of Medicine, } \\
\text { Louisville, KY }\end{array}$ & $\begin{array}{l}\text { University of Louisville School of Medicine, } \\
\text { Louisville, KY }\end{array}$ & $\begin{array}{l}\text { University of Louisville School of Medicine, } \\
\text { Louisville, KY }\end{array}$ & $\begin{array}{l}\text { University of Louisville School of Medicine, } \\
\text { Louisville, KY }\end{array}$ \\
\hline
\end{tabular}

\title{
Spur-cell anemia
}

A

59-YEAR-OLD MAN presented to the emergency department with dizziness and fatigue. He had a history of alcoholic liver disease with cirrhosis, diagnosed 1 month prior, with small esophageal varices and a Model for End-Stage Liver Disease-Sodium score of 33 (indicating a high predicted mortality risk, $66 \%$ at 90 days). There was no hematemesis or melena.

Physical examination revealed scleral icterus, mild abdominal distention, and bilateral pitting edema, with scattered bruising.

Laboratory testing revealed the following:

- Acute anemia, with a hemoglobin level of $6.3 \mathrm{~g} / \mathrm{dL}$, down from $10.6 \mathrm{~g} / \mathrm{dL} 2$ weeks earlier (reference range 13.0-17.0)

- Macrocytosis, with a mean corpuscular volume of $109 \mathrm{fL}$, up from $92 \mathrm{fL}$ (80-100)

- Red blood cell distribution width $22 \%$ $(11 \%-16 \%)$

- Reticulocyte count 9\% (0.4\%-2.0\%), absolute count $194 \times 10^{9} / \mathrm{L}(18-100)$

- Lactate dehydrogenase 412 U/L (140-280). Stable thrombocytopenia and hyperbilirubinemia were also noted. Tests for human immunodeficiency virus and hepatitis were negative.

Computed tomography showed only diffuse edema and mild ascites, without hemorrhage or fluid collections.

The patient received a transfusion of 2 units of packed red blood cells, after which his hemoglobin level was even lower- $5.9 \mathrm{~g} / \mathrm{dL}$. An additional 4 units were transfused over the next 48 hours, but his peak hemoglobin level was still only $6.5 \mathrm{~g} / \mathrm{dL}$.

Further testing showed rising bilirubin, an undetectable haptoglobin, elevated lactate dehydrogenase, and a negative direct Coombs test.

The authors report no relevant financial relationships which, in the context of their contributions, could be perceived as a potential conflict of interest. doi:10.3949/ccjm.87a.20044

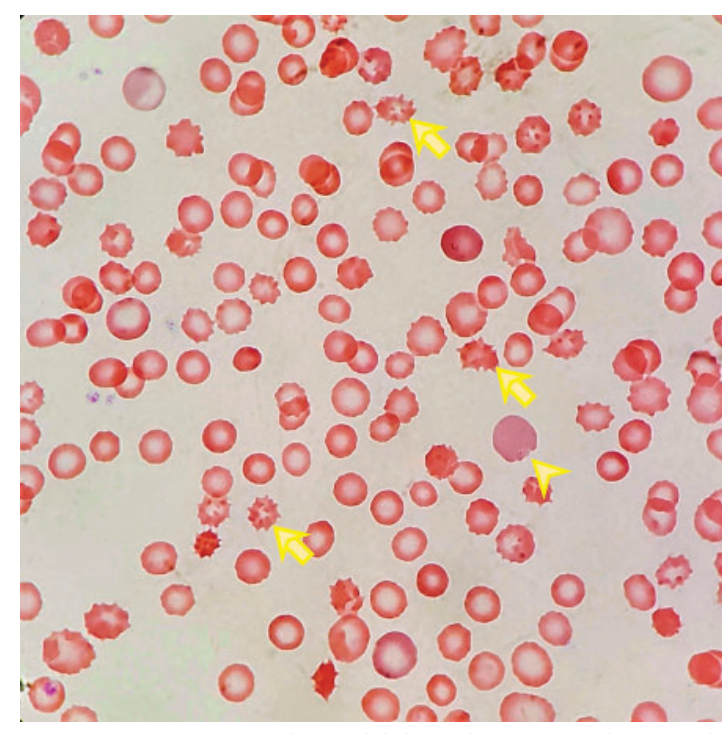

Figure 1. A peripheral blood smear showed numerous irregularly shaped erythrocytes with spinous projections ("spur cells") and increased reticulocytes.

The peripheral blood smear (Figure 1) showed numerous irregularly shaped erythrocytes with spinous projections (ie, acanthocytes, or "spur cells") and increased reticulocytes, confirming the diagnosis of spur-cell anemia.

\section{HEMOLYTIC ANEMIA IN HEPATIC FAILURE}

Hemolysis in hepatic failure is often overlooked as a cause of anemia. These patients often have decreased haptoglobin, elevated lactate dehydrogenase, and hyperbilirubinemia at baseline.

When Coombs-negative hemolysis is suspected in liver failure, the peripheral blood smear should be reviewed for morphologic abnormalities. Abnormal lipid and protein metabolism results in erythrocyte membrane defects-commonly, macrocytosis and target
A man with liver disease presents with dizziness and fatigue 
cells. These erythrocytes lose their plasticity and are deformed as they travel through the spleen, resulting in the formation of spur cells and increased clearance in the reticuloendothelial system. Zieve syndrome is a triad of jaundice, hypertriglyceridemia, and hemolysis. $^{1}$

\section{MANAGEMENT IS MAINLY SUPPORTIVE}

Spur-cell anemia is associated with a poor prognosis, and liver transplant is the only definitive management. ${ }^{2}$ Supportive management includes transfusion for symptomatic

\section{REFERENCES}

1. Zieve L. Jaundice, hyperlipemia and hemolytic anemia: a heretofore unrecognized syndrome associated with alcoholic fatty liver and cirrhosis. Ann Intern Med 1958; 48(3):471-496. doi:10.7326/0003-4819-48-3-471

2. Gerber B, Stussi G. Reversibility of spur cell anemia Blood 2011; 118(16):4304. doi:10.1182/blood-2010-11-321034

3. Karam D, Swiatkowski S, Purohit P, Agrawal B. Highdose steroids as a therapeutic option in the management of spur cell haemolytic anaemia. BMJ Case Rep 2018; 2018:bcr2017223281. doi:10.1136/bcr-2017-223281 anemia, discontinuation of bone marrow-suppressive medications and alcohol, and appropriate treatment for the primary cause of liver disease. Medical management with prednisolone or pentoxifylline is based only on limited case reports, and further research is needed. ${ }^{3,4}$

Recurrence of spur-cell anemia after transplant can herald graft failure. ${ }^{5}$

\section{Our patient's care}

Our patient was not a candidate for transplant because of his ongoing alcohol use. He was enrolled in palliative care and died 1 month later.

4. Aihara K, Azuma H, lkeda $Y$, et al. Successful combina tion therapy-flunarizine, pentoxifylline, and cholestyramine-for spur cell anemia. Int J Hematol 2001; 73(3):351-355. doi:10.1007/BF02981961

5. Malik P, Bogetti D, Sileri $\mathbf{P}$, et al. Spur cell anemia in alcoholic cirrhosis: cure by orthotopic liver transplantation and recurrence after liver graft failure. Int Surg 2002 87(4):201-204. pmid:12575799

Address: Satish Maharaj MD, James Graham Brown Cancer Center, University of Louisville School of Medicine, 529 S Jackson Street, LRC 4th Floor L-18, Louisville, KY 40207;

satishsmaharaj@gmail.com 